\title{
RESEARCH
}

Open Access

\section{Mesenchymal stem cells overexpressing hepatocyte nuclear factor-4 alpha alleviate liver injury by modulating anti- inflammatory functions in mice}

Zhenxiong Ye ${ }^{1 \dagger}$, Wenfeng $\mathrm{Lu}^{1,2+}$, Lei Liang ${ }^{1,2 \dagger}$, Min Tang ${ }^{1}$, Yunfeng Wang ${ }^{1}$, Zhen Li ${ }^{1}$, Heping Zeng ${ }^{1}$, Aili Wang ${ }^{1}$, Moubin Lin ${ }^{1}$, Lei Huang ${ }^{1}$, Hui Wang ${ }^{1}$ and Hai Hu ${ }^{3 *}$

\begin{abstract}
Background: Mesenchymal stem cells (MSCs) can migrate to tissue injury sites where they can induce multipotential differentiation and anti-inflammation effects to treat tissue injury. When traditional therapeutic methods do not work, MSCs are considered to be one of the best candidates for cell therapy. MSCs have been used for treating several injury- and inflammation-associated diseases, including liver cirrhosis. However, the therapeutic effect of MSCs is limited. In some cases, the anti-inflammatory function of naive MSCs is not enough to rescue tissue injury.

Methods: Carbon tetrachloride $\left(\mathrm{CCl}_{4}\right)$ was used to establish a mouse liver cirrhosis model. Enhanced green fluorescence protein (EGFP) and hepatocyte nuclear factor-4a (HNF-4a) overexpression adenoviruses were used to modify MSCs. Three weeks after liver injury induction, mice were injected with bone marrow MSCs via their tail vein. The mice were then sacrificed 3 weeks after MSC injection. Liver injury was evaluated by measuring glutamicpyruvic transaminase (ALT) and glutamic oxalacetic transaminase (AST) levels. Histological and molecular evaluations were performed to study the mechanisms.

Results: We found that HNF-4a-overexpressing MSCs had a better treatment effect than unmodified MSCs on liver cirrhosis. In the $\mathrm{CCl}_{4}$-induced mouse liver injury model, we found that HNF-4a-MSCs reduced inflammation in the liver and alleviated liver injury. In addition, we found that HNF-4a promoted the anti-inflammatory effect of MSCs by enhancing nitric oxide synthase (iNOS) expression, which was dependent on the nuclear factor kappa B (NF-kB) signalling pathway.

Conclusions: MSCs overexpressing HNF-4a exerted good therapeutic effects against mouse liver cirrhosis due to an enhanced anti-inflammatory effect. Gene modification is likely a promising method for improving the effects of cell therapy.
\end{abstract}

Keywords: Mesenchymal stem cells, Hepatocyte nuclear factor-4 alpha, Liver injury, Immune regulation

\footnotetext{
* Correspondence: huhaidfyy@sina.com

${ }^{\dagger}$ Zhenxiong Ye, Wenfeng Lu and Lei Liang contributed equally to this work.

${ }^{3}$ Center of Gallbladder Disease, Shanghai East Hospital, Tongji University

School of Medicine, $150 \mathrm{Ji}$ Mo Road, Shanghai 201200, China

Full list of author information is available at the end of the article
}

(c) The Author(s). 2019 Open Access This article is distributed under the terms of the Creative Commons Attribution 4.0 International License (http://creativecommons.org/licenses/by/4.0/), which permits unrestricted use, distribution, and reproduction in any medium, provided you give appropriate credit to the original author(s) and the source, provide a link to the Creative Commons license, and indicate if changes were made. The Creative Commons Public Domain Dedication waiver (http://creativecommons.org/publicdomain/zero/1.0/) applies to the data made available in this article, unless otherwise stated. 


\section{Background}

Liver cirrhosis is the end stage of chronic liver injury and is characterized by liver structure disorder, nodule formation and liver function loss, most likely resulting in liver failure or hepatocellular carcinoma (HCC) [1-3]. Currently, orthotopic liver transplantation (OLT) is considered to be the most effective treatment for liver cirrhosis; however, it is limited by donor shortages, immunological rejection and expensive medical costs [4].

In recent years, stem cell transplantation has become a promising alternative option for most diseases. MSCs have been reported to be an effective treatment for liver injury [5] because they are easy to isolate, proliferate well in vitro and have low immunogenicity and no ethical issues [6]. MSCs have been shown to be able to migrate to injury sites and exert anti-inflammatory or differentiation effects. MSCs have been shown to be highly effective in treating tissue injury and degenerative diseases, such as myocardial infarction, spinal cord injury, bone damage, cornea damage, liver cirrhosis and other tissue injuries [6]. However, there are some issues limiting the use of MSCs [7]. It has been reported that $1-5 \times 10^{6}$ cells $/ \mathrm{kg}$ are needed to treat patients $[8,9]$. As a result, MSCs need to be expanded beyond passage 5 to generate sufficient numbers for clinical treatment. However, reports have demonstrated that adult BM-MSCs lose their immunosuppressive capabilities in early passages (5-7) [10]. In addition, MSCs from different sources have been shown to differentially regulate the immune response [11]. Thus, naive MSCs are not enough to rescue injury in some cases. However, there are some things that can be done to promote the anti-inflammatory effects of MSCs.

HNF- $4 \alpha$ is a nuclear transcription factor that can initiate the expression of a series of mature liver cell markers and plays an important role in liver cell maturation [12, 13]. Studies have reported that HNF-4 $\alpha$ overexpression via adenovirus can reduce liver damage and treat liver cancer [14], but both lentiviruses and adenoviruses have certain risks for direct application in vivo, such as tumourigenesis and strong inflammatory responses.

In the present study, to eliminate the risks of virus application in vivo and to enhance the treatment of MSCs, we used an adenovirus as a vector for overexpressing HNF-4 $\alpha$ in MSCs. We transplanted bone marrow MSCs overexpressing HNF-4 $\alpha$ (HNF-4 $\alpha$-MSCs) into mice with chronic liver injury caused by $\mathrm{CCl}_{4}$. An adenovirus overexpressing EGFP was used as a control. To our surprise, the therapeutic effect of MSCs on liver injury after transfection with the HNF- $4 \alpha$-adenovirus was highly improved. However, the mechanism requires further study. We focused on changes in hepatocyte differentiation and inflammation regulation. Surprisingly, we found that hepatocyte differentiation induction via HNF-4 $\alpha$ in vivo was not the key reason why MSCs reduced liver injury.
Increased immune regulation by MSCs was found to play a dominant role in liver injury repair. Finally, we demonstrated that HNF- $4 \alpha$ could facilitate the anti-inflammatory function of MSCs by increasing the protein expression of inducible nitric oxide synthase (iNOS) by activating the NF-kB signalling pathway.

\section{Materials and methods}

\section{Animals and experimental design}

Male C57BL/6 mice (6-8 weeks old, weighing 20-25 g) were purchased from the Shanghai Laboratory Animal Center and housed in pathogen-free conditions with a $12 / 12 \mathrm{~h}$ light/dark illumination cycle and free access to food and water. Animal protocols were approved by the TongJi University Animal Care Committee, and all animal experiments conformed to the relevant regulatory standards. $\mathrm{CCl}_{4}$ is commonly used for mouse liver injury models. Mice were separated into four groups: control group (olive oil was administered via intragastric gavage), cirrhosis group $\left(20 \% \mathrm{CCl}_{4}\right.$ was used at a concentration of $5 \mathrm{~mL} / \mathrm{kg}$ twice a week), cirrhosis + EGFP-MSC group $\left(1 \times 10^{6}\right.$ EGFP-MSCs were injected via tail vein at the third week) and cirrhosis + HNF-4 $\alpha$-MSC group $\left(1 \times 10^{6} \mathrm{HNF}-4 \alpha\right.$-MSCs were injected via tail vein at the third week). MSCs at passage 4 were transfected with adenovirus and then injected into the mice. To assess the effect of cell therapy, the mice were sacrificed 3 weeks after injection.

\section{Isolation and culture of primary MSCs}

Bone marrow MSCs were isolated from male C57BL/ 6 mice according to Heng Zhu's protocol [15]. Bone marrow was acquired by flushing the femurs and tibias of mice with culture medium. Then, the cells were blown into a single cell suspension and seeded into a $10-\mathrm{cm}$ dish with $20 \mathrm{~mL}$ medium. Five days later, the medium was changed, and the cells were passaged when confluent. The cells were considered MSCs and used for experiments after 3 passages. MSCs were identified by testing their ability to differentiate to adipocytes and osteocytes.

\section{Recombinant adenovirus}

A recombinant HNF-4 $4 \alpha$ overexpression adenovirus and control adenovirus were purchased from Genechem Biotech, Inc. Shanghai, China. MSC infection (passage 4) was performed according to the manufacturer's protocol.

\section{Histological and immunohistochemical analyses}

Mouse liver tissues were fixed in formalin for $24 \mathrm{~h}$ and embedded in paraffin. Five-micron-thick sections were made from paraffin-embedded liver tissues and then stained with haematoxylin and eosin to detect histological structure and 
with Sirius red to detect liver fibrosis. For immunohistochemical staining, the sections were incubated with primary antibodies to ALB (ab192603, 1:300, Abcam) and CD68 (ab955, 1:200, Abcam) according to previously described protocols [16].

\section{Biochemical analysis}

Mouse blood was collected when the mice were sacrificed. The samples were kept at $4{ }^{\circ} \mathrm{C}$ overnight and then centrifuged at $3000 \mathrm{rpm}$ for $10 \mathrm{~min}$ for serum separation. To measure liver injury, the serum samples were analysed for glutamic-pyruvic transaminase and glutamic oxalacetic transaminase levels by a biochemical analyser (DRI-CHEM 55500 V, Fuji Medical System, Japan).

\section{Transwell assay}

Ten thousand EGFP-MSCs and HNF-4 $\alpha$-MSCs (both passage 4) were plated into the upper chamber of a 24-well plate. Culture medium with 5\% FBS was added to the lower chamber, while serum-free medium was added into the upper chamber. After $72 \mathrm{~h}$, the migrated cells were stained with crystal violet and counted.

\section{CCK-8 assay}

A total of 3000 MSCs, EGFP-MSCs and HNF-4 $\alpha$-MSCs (all passage 4) were plated into a 96-well plate; 6 replicates per group were used for this experiment. After $48 \mathrm{~h}$, CCK-8 solution was added to the plate at a ratio of $100 \mu \mathrm{L}$ fresh serum-free culture medium: $10 \mu \mathrm{L}$ CCK- 8 solution, and the cells were incubated for $1 \mathrm{~h}$ in a $37^{\circ} \mathrm{C}$ incubator. Then, the OD values were detected at a wavelength of $450 \mathrm{~nm}$.

\section{MSC co-culture with A1.1 cells}

MSCs (passage 4) were treated with $10 \mathrm{ng} / \mathrm{mL}$ IFN- $\gamma$ and $10 \mathrm{ng} / \mathrm{mL}$ TNF- $\alpha$ for $12 \mathrm{~h}$ and then co-cultured with A1.1 cells at a ratio of 1 MSC:10 A1.1 cells for $24 \mathrm{~h}$. Then, the proliferation of A1.1 cells was measured by ${ }^{3} \mathrm{H}-\mathrm{Tdr}$ assay.

\section{${ }^{3} \mathrm{H}-\mathrm{Tdr}$ assay}

A total of $0.5 \mu \mathrm{Ci}$ of ${ }^{3} \mathrm{H}$-thymidine was added to each well of a 96-well plate $6 \mathrm{~h}$ before the cultures were terminated by freezing. The cells were harvested after the plates were thawed, and incorporated ${ }^{3} \mathrm{H}-\mathrm{Tdr}$ was assessed with a Wallac Microbeta scintillation counter (Perkin-Elmer, Waltham, MA, USA).

\section{Nitrate detection assay}

MSCs (passage 4) were plated into 6-well plates, and when the cells were $80 \%$ confluent, $10 \mathrm{ng} / \mathrm{mL}$ IFN- $\gamma$ and $10 \mathrm{ng} / \mathrm{mL}$ TNF- $\alpha$ were added for $12 \mathrm{~h}$. Then, $1 \mathrm{~mL}$ of fresh serum-free conditioned medium was added to the plate. Conditioned medium was collected after $24 \mathrm{~h}$.
$\mathrm{NO}$ in conditioned medium was detected by Griess assay (S0021, Beyotime, China) according to the manufacturer's protocol.

\section{Real-time PCR}

MSCs (passage 4) were treated with $10 \mathrm{ng} / \mathrm{mL}$ IFN- $\gamma$ and $10 \mathrm{ng} / \mathrm{mL}$ TNF- $\alpha$ for $10 \mathrm{~h}$ and $24 \mathrm{~h}$. Total RNA was isolated with Trizol and reverse-transcribed into cDNA with a Bestar qPCR RT kit. mRNA expression of iNOS was detected by RT-PCR using Bestar real-time PCR master mix with an ABI Prism 7300 system. The primers used were as follows: iNOS, sense, GTTC TCAGCCCAACAATACAAGA, antisense, GTGGACGG GTCGATGTCAC; GA PDH, sense, AGGTCGGTGTGA ACGGATTTG, antisense, TGTAGACCATGTAGTTGAG GTCA.

\section{Western blotting assay}

MSCs (passage 4) were treated with $10 \mathrm{ng} / \mathrm{mL}$ IFN- $\gamma$ and $10 \mathrm{ng} / \mathrm{mL}$ TNF- $\alpha$ for $2 \mathrm{~h}$ and $24 \mathrm{~h}$. Total protein was acquired with RIPA buffer and quantified by BCA assay. The same amount of protein was analysed for expression of iNOS (ab49999, 1:1000, Abcam) and IкB- $\alpha$ (4812S, 1:1000, Cell Signaling Technology) by SDS-PAGE, and GAPDH was used as a control. The assays were performed according to previously described protocols [16].

\section{Cytokine detection}

Serum cytokines were assayed by a Bio-Plex Pro Mouse Cytokine 23-plex Assay (M60009RDPD) using Luminex Technology according to the manufacturer's protocol (Bio-Plex, Bio-Rad Laboratories).

\section{Immunofluorescence assay}

MSCs (passage 4) were plated into 48-well plates, and when the cells had adhered to the plate, $10 \mathrm{ng} / \mathrm{mL}$ IFN- $\gamma$ and $10 \mathrm{ng} / \mathrm{mL}$ TNF- $\alpha$ were added to the medium. After $2 \mathrm{~h}$, the cells were fixed and blotted with $1 \%$ BSA at $37^{\circ} \mathrm{C}$ for $30 \mathrm{~min}$. Then, the cells were incubated with P65 (8242S, 1:200, Cell Signaling Technology) at $4{ }^{\circ} \mathrm{C}$ overnight. The cells were washed with PBS three times and then incubated with a fluorescent antibody (A11011, 1:200, Life Technologies) at $37^{\circ} \mathrm{C}$ for $30 \mathrm{~min}$. Finally, DAPI was used to stain the nuclei.

\section{Statistical analyses}

All experiments were performed more than three times. Three technical replicates were performed in each experiment. Student's $t$ test was performed to analyse the differences between different groups. ${ }^{*} P<0.05$ and ${ }^{* *} P<0.01$ represent significant differences. 


\section{Results}

HNF-4a-MSCs promoted liver injury repair

Mesenchymal stem cells (MSCs) were isolated from the bone marrow of 6-8-week-old mice. After passaging three times, MSCs were identified by their ability to differentiate into adipocytes and osteoblasts (Additional file 1: Figure S1). MSCs were transfected with adenovirus carrying HNF-4 $\alpha$ (EGFP was used as a control). The efficiency of transfection was confirmed by fluorescent analysis and western blotting assay (Additional file 2: Figure S2). To determine the role of MSCs overexpressing HNF-4 $\alpha$ in liver injury repair, we established a mouse liver injury model by using $\mathrm{CCl}_{4}$ administration and injected $1 \times 10^{6}$ cells on the third week. We measured ALT and AST levels 3 weeks after cell administration. As shown in Fig. 1a, EGFP-MSCs reduced ALT and AST levels slightly, whereas HNF-4 $\alpha$-MSCs reduced ALT and AST levels to a greater extent. At the same time, we detected liver pathological alterations and liver fibrosis. As shown in Fig. 1b, c and d, EGFP-MSCs could reduce the hepatocyte necrosis and liver fibrosis induced by $\mathrm{CCl}_{4}$, and HNF-4 $\alpha$ enhanced the effect of MSCs. In general, the above results suggested that EGFP-MSCs could alleviate liver injury and promote liver injury repair, while HNF-4 $\alpha-\mathrm{MSCs}$ enhanced the liver injury repair effect of MSCs.

\section{HNF-4a did not affect MSC homing}

As demonstrated before [17, 18], only when MSCs migrate to the injury site can their damage repair function be performed. Therefore, we detected the homing of MSCs to liver injury sites at different times. We tested MSC migration in vivo at 3 days and 7 days after their tail vein administration. Fluorescent observation of frozen sections of the liver showed that there was no difference between EGFP-MSC and HNF- $4 \alpha-$ MSC recruitment at both 3 days and 7 days (Fig. 2a, b). We also detected the migration function of MSCs in vitro using a transwell assay. After $72 \mathrm{~h}$, the migrated cells were counted. The results showed that there was no significant difference

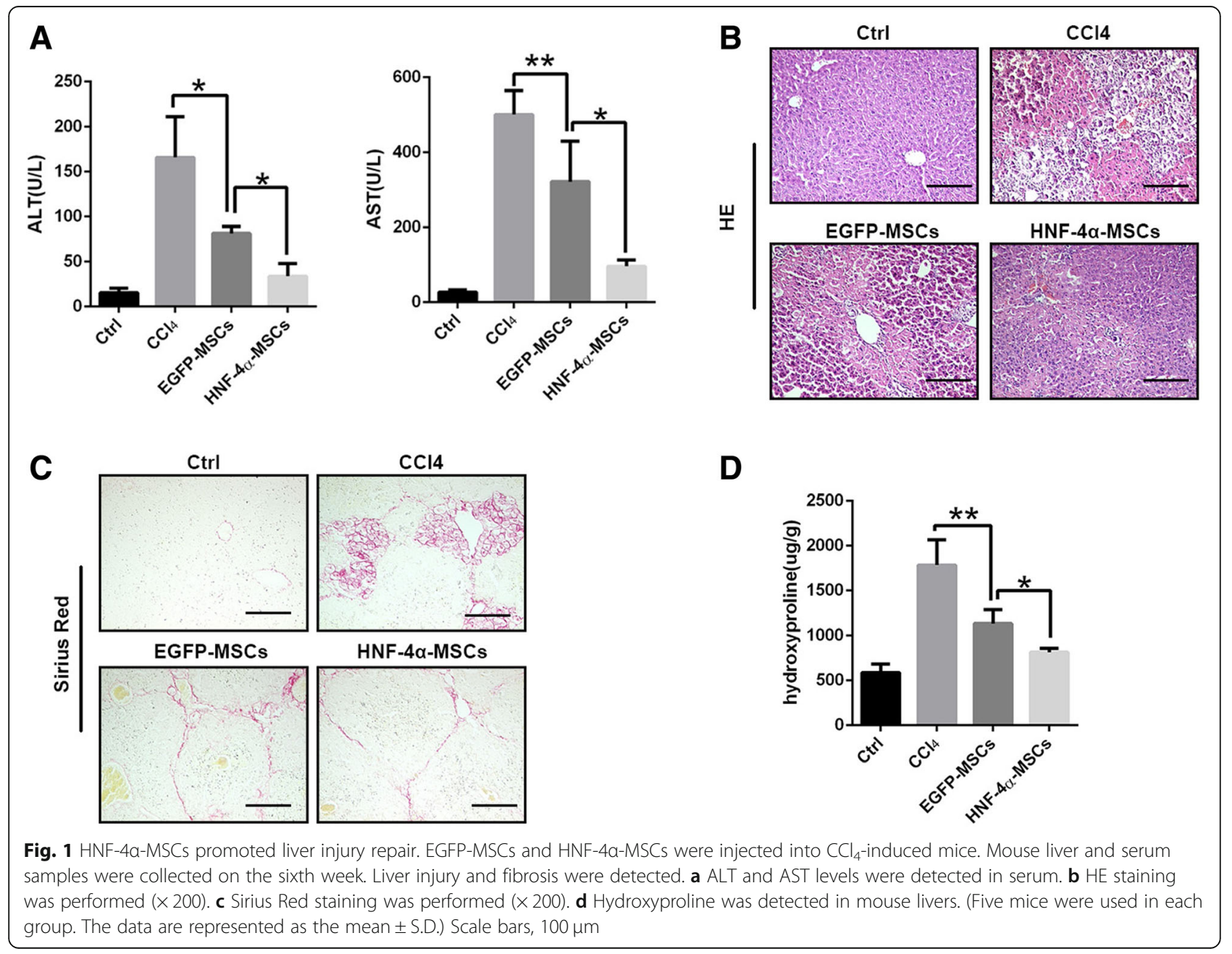




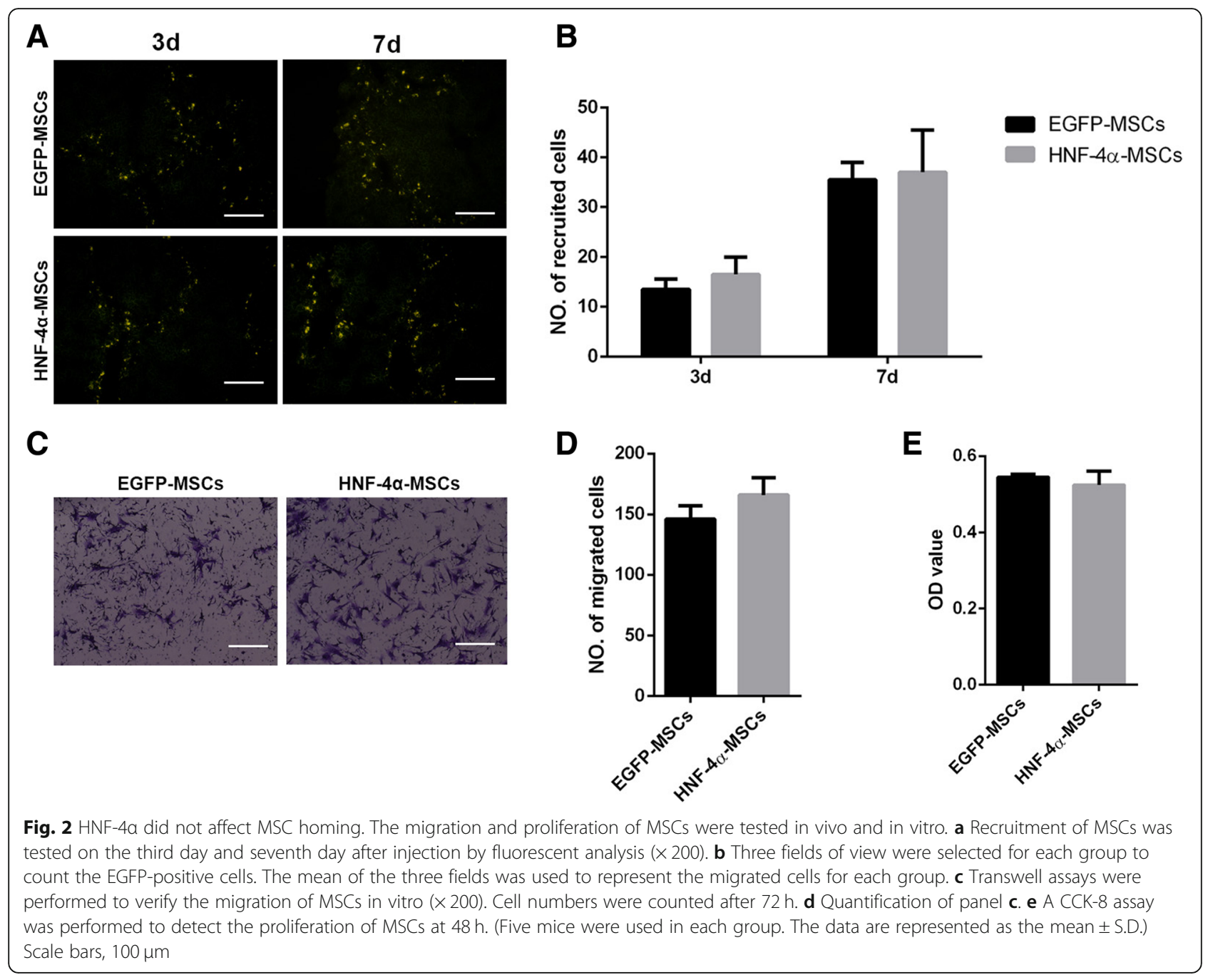

between the two groups (Fig. 2c, d). Furthermore, we tested the role of HNF-4 $\alpha$ in the proliferation of MSCs by CCK- 8 assay. MSCs, EGFP-MSCs and HNF-4 $\alpha$-MSCs were plated into 96 -well plates, and $48 \mathrm{~h}$ later, a CCK8 assay was performed to detect cell viability. HNF- $4 \alpha$ had no effect on the proliferation of MSCs (Fig. 2e).

\section{HNF-4a-MSCs inhibited Kupffer cell-associated inflammation}

Inflammation is the main cause of liver injury, and MSCs were demonstrated to repair tissue injury by modulating inflammation $[17,19,20]$. We detected proinflammatory factors in mouse serum samples from different groups. As shown in Fig. 3a, HNF- $4 \alpha-$ MSCs reduced the inflammatory factors in mouse serum samples considerably. As HNF- $4 \alpha$ is a transcription activator that regulates hepatic differentiation, whether HNF- $4 \alpha$ promotes hepatocyte differentiation in MSCs deserves consideration. First, we detected the expression of the hepatocyte marker ALB in the mouse livers. As shown in Fig. 3b, there were no differences in the expression of ALB, which suggested that hepatocyte differentiation did not reduce liver injury in the HNF- $4 \alpha-M S C$ group. Kupffer cells are the main macrophage type in the liver sinusoids and contribute to host defence and inflammation accumulation [21]. CD68 immunohistochemistry staining showed that $\mathrm{CCl}_{4}$ induced Kupffer cell activation, and EGFP-MSCs inhibited the activation of Kupffer cells, which was enhanced by HNF- $4 \alpha$. In the HNF- $4 \alpha-$ MSC group, Kupffer cell activation was reduced to a lower level (Fig. 3c, d). This is probably the reason why MSCs reduced liver inflammation.

HNF-4a-MSCs exerted enhanced anti-inflammatory effects by increasing iNOS expression

To verify how MSCs inhibited Kupffer cell activation, we detected the anti-inflammatory effect of HNF$4 \alpha$-MSCs in vitro by co-culture with lymphocyte A1.1 cells. As shown in previous studies, MSCs exert their 


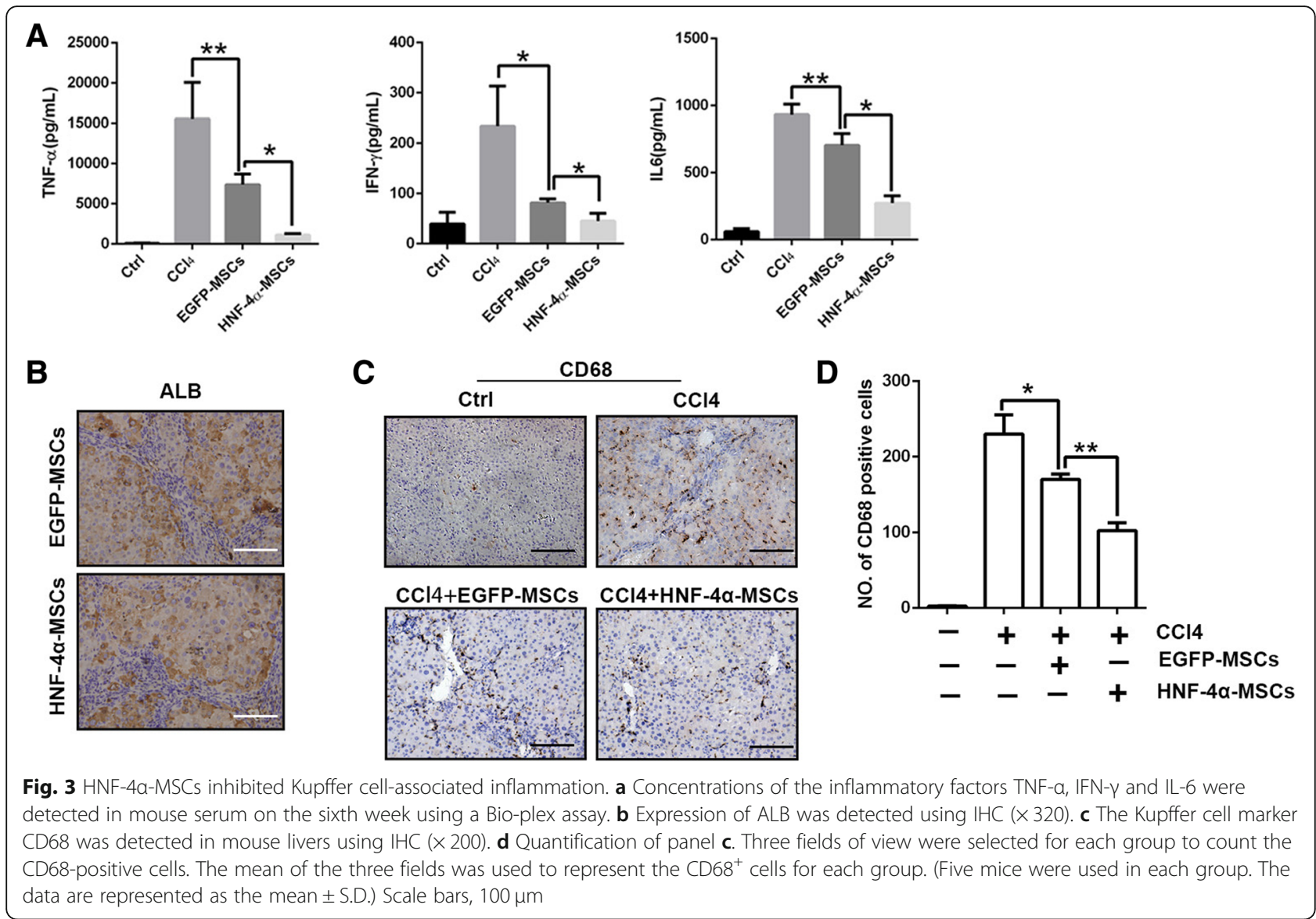

anti-inflammatory function only after stimulation by inflammatory cytokines. MSCs stimulated with IFN- $\gamma$ plus TNF- $\alpha(10 \mathrm{ng} / \mathrm{mL})$ were co-cultured with A1.1 cells at a ratio of 1 MSCs:10 A1.1 cells. The ${ }^{3} \mathrm{H}-\mathrm{Tdr}$ assay results showed that HNF-4 $\alpha$-MSCs induced significantly more anti-inflammatory effects than EGFP-MSCs (Fig. 4a). Then, we detected iNOS expression in MSCs. Both EGFP-MSCs and HNF- $4 \alpha-$ MSCs were treated with the inflammatory factors IFN- $\gamma$ and TNF- $\alpha(10 \mathrm{ng} / \mathrm{mL})$ for the indicated time. The expression of iNOS was higher in HNF-4 $\alpha$-MSCs than in control cells at $24 \mathrm{~h}$. At the same time, we detected the concentration of nitrite in the conditioned medium of MSCs, which represents the NO content. NO is the key factor through which MSCs exert their anti-inflammatory effects [18]. After inflammatory factor stimulation, nitrate was increased significantly in the conditioned medium. Compared with EGFP-MSCs, HNF-4 $\alpha$ MSCs secreted more NO (Fig. 4d).

\section{HNF-4a promoted the immune regulation of MSCs through NF-KB signalling}

The expression of iNOS can be regulated by several signalling pathways, including NF- $\mathrm{B}$, CCAAT enhancer binding protein beta $(\mathrm{C} / \mathrm{EBP} \beta)$, and signal transducer and activator of transcription 1 (STAT1) [22]. To investigate how HNF- $4 \alpha$ overexpression regulates iNOS expression in MSCs, we first analysed the NF- $\mathrm{kB}$ signalling pathway. Interestingly, as shown in Fig. 5 a and b, the immunofluorescence staining results showed that after treatment with inflammatory factors for $2 \mathrm{~h}$, more P65 was translocated into the nucleus in HNF- $4 \alpha-$ MSCs. P65 translocation to the nucleus indicates NF- $\mathrm{kB}$ activation. In addition, we measured I $\mathrm{KB}-\alpha$ expression after IFN- $\gamma$ and TNF- $\alpha$ treatment for $2 \mathrm{~h}$. Western blotting assays revealed that the expression of IкB- $\alpha$ was downregulated in HNF-4 $\alpha$-MSCs (Fig. $5 \mathrm{c}$ ), which suggested NF- $\mathrm{kB}$ signalling pathway activation. In addition, we blocked the NF- $\mathrm{kB}$ signalling pathway using BAY 11-7082. We found that BAY 11-7082 treatment for $2 \mathrm{~h}$ effectively increased the level of IкB- $\alpha$ in HNF-4 $\alpha$-MSCs. In parallel, the expression of iNOS in HNF-4 $\alpha$-MSCs after IFN- $\gamma$ and TNF- $\alpha$ treatment for $24 \mathrm{~h}$ was inhibited (Fig. $5 \mathrm{~d}$ ). As a result, HNF- $4 \alpha$ upregulated the expression of iNOS via activation of the NF- $\mathrm{kB}$ signalling pathway.

\section{Discussion}

Mesenchymal stem cells are a population of adult stem cells with self-renewal and multiple differentiation 

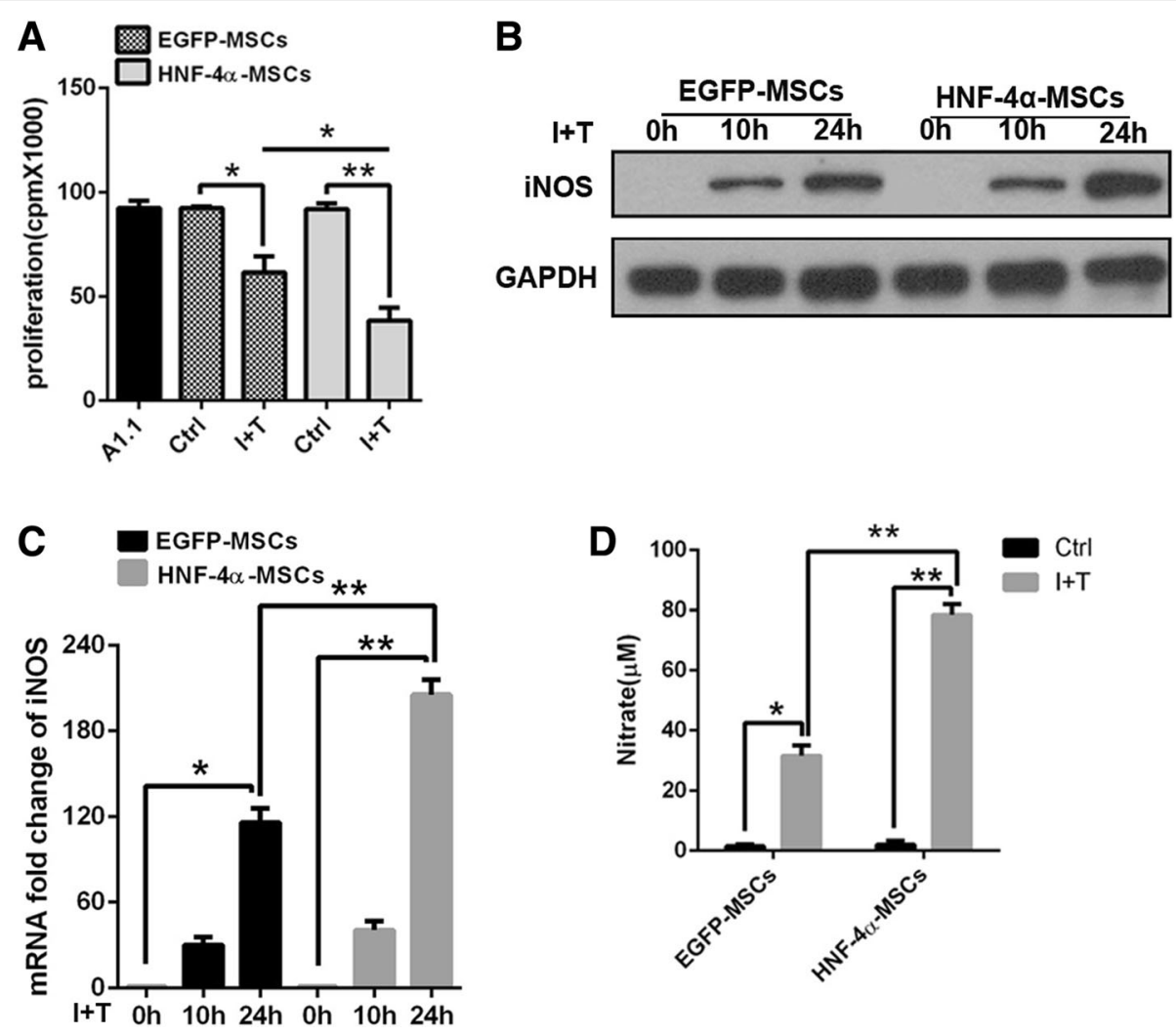

Fig. 4 HNF-4a-MSCS exerted enhanced anti-inflammatory effects by increasing iNOS expression. a MSCs were treated with $10 \mathrm{ng} / \mathrm{mL} \mathrm{IFN}-\mathrm{\gamma}$ and $10 \mathrm{ng} / \mathrm{mL}$ TNF- $\mathrm{a}$ for $12 \mathrm{~h}$ and then co-cultured with A1.1 cells. After $24 \mathrm{~h}$, the proliferation of A1.1 cells was detected using a ${ }^{3} \mathrm{H}-\mathrm{Tdr}$ assay. b, c MSCs were treated with $10 \mathrm{ng} / \mathrm{mL}$ IFN- $\gamma$ and $10 \mathrm{ng} / \mathrm{mL}$ TNF-a for $10 \mathrm{~h}$ and $24 \mathrm{~h}$. The expression of iNOS was detected using western blotting and RT-PCR assays. GAPDH was used as an internal control. d Conditioned medium from MSCs treated with $10 \mathrm{ng} / \mathrm{mL}$ IFN- $\gamma$ and $10 \mathrm{ng} / \mathrm{mL}$ TNF- $a$ was collected after $24 \mathrm{~h}$. I+T, IFN- $\gamma$ and TNF- $a$. Nitrate levels were detected (The data are represented as the mean \pm S.D.)

abilities. They can differentiate into mesodermal cells, such as bone, adipocytes, cartilage [23] and skeletal muscle [24]. MSCs can also differentiate into entodermal [25] and ectodermal [26] cells under special conditions. They have been demonstrated to be isolated from the bone marrow, umbilical cord, adipose tissue, liver [27], muscle [28], heart [29] and other tissues. MSCs can also be expanded easily in vitro. MSCs exhibit strong injury tropism and immunosuppression properties [30, 31]. Due to the characteristics described above, MSCs have great potential for use in clinical therapy.

Liver cirrhosis is an important health issue that commonly leads to liver failure and HCC. Currently, orthotopic liver transplantation is the most effective treatment, but this method is limited by donor shortages and immunological rejection. Cell therapy has become increasingly popular because of its efficiency and few side effects. Mesenchymal stem cells are the most popular stem cells for cell therapy. They can migrate to tissue injury sites and repair liver injury by differentiating into multiple types of cells and performing immunity regulation functions. However, not all of the effects of cell therapy are satisfactory.

Gene therapy is now another efficient method for treating some diseases. HNF- $4 \alpha$ has been shown to be useful in treating HCC [14]. However, the safety concerns regarding virus vectors are disturbing. MSCs are a good vector of genes because of their low immunity and low tumourigenesis [6].

In our study, we found that HNF-4 $\alpha$ overexpression facilitated the therapeutic effect of MSCs in liver cirrhosis. The liver function index, pathology structure and fibrosis indicated that HNF- $4 \alpha$ accelerated the repair function of MSCs in liver injury. Inflammatory factor detection in mouse serum showed that inflammation was further reduced after HNF- $4 \alpha-$ MSC transplantation and that macrophages were inhibited. In addition, enhanced repair function is not dependent on increased MSC migration, and HNF- $4 \alpha$ does not affect MSC proliferation. Surprisingly, we found that there was no difference in ALB expression between the MSC and HNF-4 $\alpha$-MSC groups, which suggested 


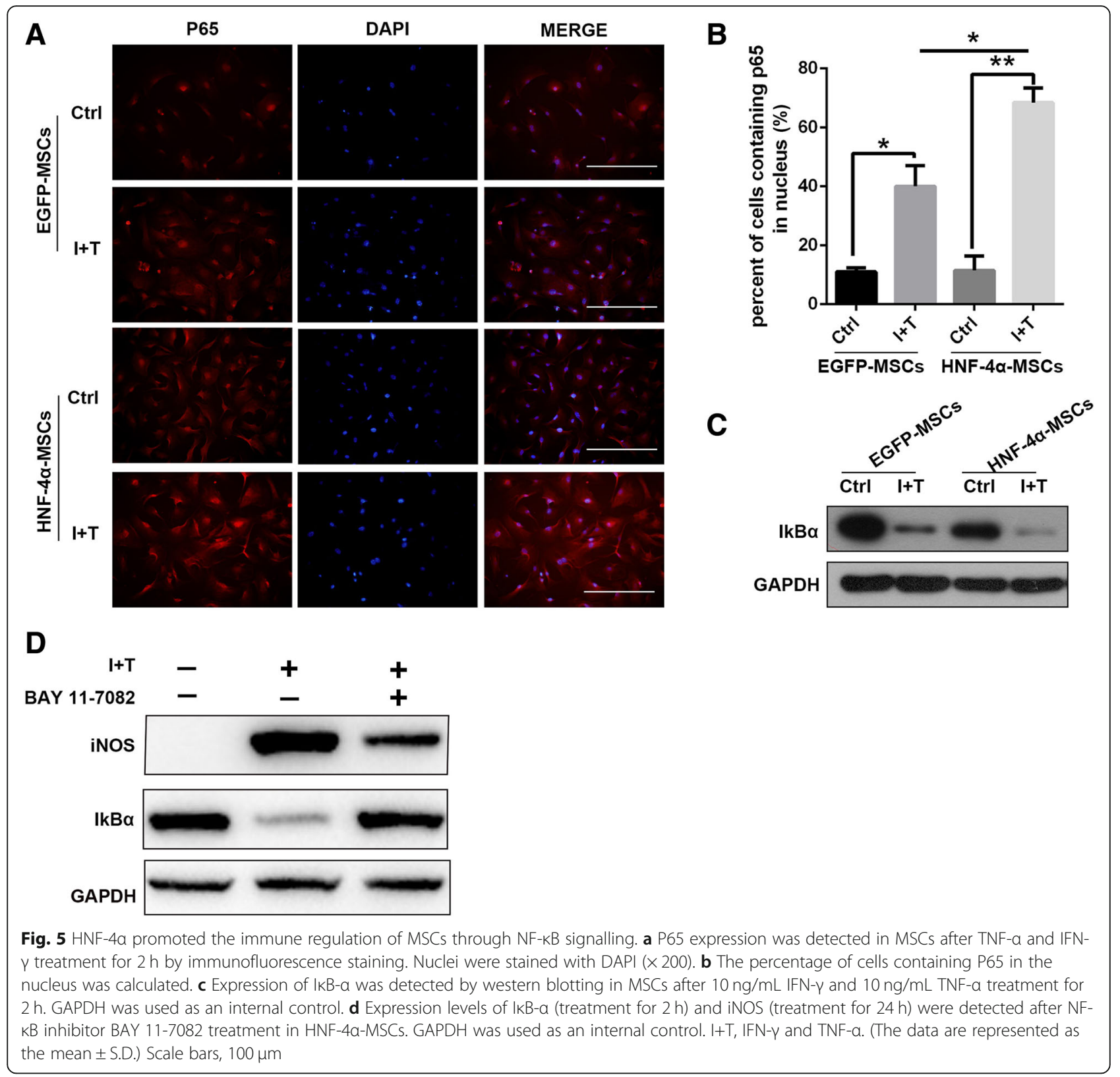

that the hepatocyte differentiation of MSCs is not the key underlying mechanism. However, we found that HNF-4 $\alpha$-MSCs had enhanced immunosuppression ability.

$\mathrm{NO}$ is an important factor that kills immune cells [18]. Further study showed that HNF- $4 \alpha$ promoted iNOS expression through the $\mathrm{NF}-\mathrm{kB}$ pathway. In HNF-4 $\alpha$-MSCs, more p65 was relocated to the nucleus. When an NF-kB inhibitor was used, iNOS expression was reduced. The above data suggested that HNF- $4 \alpha$ promoted the iNOS-dependent anti-inflammatory effect of MSCs by activating the NF- $\mathrm{BB}$ signalling pathway.
In conclusion, MSC modification by gene editing could enhance their therapeutic effect in liver cirrhosis. However, cell therapy combined with gene therapy needs further study.

\section{Conclusions}

In this study, we found that MSCs overexpressing HNF-4 $\alpha$ exerted better therapeutic effects than control MSCs against mouse liver cirrhosis by enhancing their NF-kB-dependent anti-inflammatory effect. Thus, gene modification is likely a promising method for improving the effects of cell therapy. 


\section{Additional files}

Additional file 1: Figure S1. Identification of MSCs according to their differentiation potential. MSCs were isolated from mouse bone marrow and identified after passaging three times. MSCs were induced to differentiate into adipocytes and osteoblasts with differentiation medium for 7 days and 21 days, respectively, and then stained with oil red and alizarin red. (JPG $697 \mathrm{~kb}$ )

Additional file 2: Figure S2. Confirmation of adenovirus transfection. MSCs were transfected with adenoviruses carrying EGFP and EGFP-HNF-4a. (A) Fluorescence was observed under a fluorescence microscope $(\times 200)$. (B) HNF-4a protein levels were detected by western blotting. (JPG 246 kb)

\section{Abbreviations}

AV: Adenovirus; C/EBP $\beta$ : CCAAT enhancer binding protein beta; $\mathrm{CCl}_{4}$ : Carbon tetrachloride; EGFP: Enhanced green fluorescence protein;

HCC: Hepatocellular carcinoma; HNF-4a: Hepatocyte nuclear factor-4a; iNOS: Inducible nitric oxide synthase; MSCs: Mesenchymal stem cells; NFkB: Nuclear factor kappa B; OLT: Orthotopic liver transplantation; STAT1: Signal transducer and activator of transcription 1

\section{Acknowledgements}

Not applicable.

\section{Funding}

This project was supported by Shanghai Science and Technology Committee (Grant No. 15DZ1941204).

\section{Availability of data and materials}

Please contact the author for data requests.

\section{Authors' contributions}

$Z Y, W L, L L$ and $H H$ conceived and designed the study. ZY, WL and LL wrote the manuscript. MT and $Y W$ helped to proofread the manuscript. $Z \mathrm{~L}, \mathrm{HZ}$, AW and HW helped to perform the experiments. ML and LH helped to modify the manuscript. All authors read and approved the final manuscript.

\section{Ethics approval and consent to participate}

The study was carried out strictly according to recommendations from the Guide for the Care and Use of Laboratory Animals of the National Institutes of Health.

\section{Consent for publication}

Not applicable.

\section{Competing interests}

The authors declare that they have no competing interests.

\section{Publisher's Note}

Springer Nature remains neutral with regard to jurisdictional claims in published maps and institutional affiliations.

\section{Author details}

'Department of General Surgery, Yangpu Hospital, Tongji University School of Medicine, 450 Teng Yue Road, Shanghai 200090, China. ${ }^{2}$ Department of Hepatobiliary Surgery, Eastern Hepatobiliary Surgery Hospital, The Second Military Medical University, Shanghai, China. ${ }^{3}$ Center of Gallbladder Disease, Shanghai East Hospital, Tongji University School of Medicine, $150 \mathrm{Ji}$ Mo Road, Shanghai 201200, China.

Received: 3 December 2018 Revised: 3 May 2019 Accepted: 10 May 2019 Published online: 27 May 2019

\section{References}

1. Bolondi L, Gramantieri L. From liver cirrhosis to HCC. Intern Emerg Med. 2011;6(Suppl 1):93-8.

2. Iredale JP. Cirrhosis: new research provides a basis for rational and targeted treatments. BMJ. 2003;327(7407):143-7.
3. Cui $L$, et al. Serum miR-335 level is associated with the treatment response to trans-arterial chemoembolization and prognosis in patients with hepatocellular carcinoma. Cell Physiol Biochem. 2015; 37(1):276-83.

4. Berardis S, et al. Use of mesenchymal stem cells to treat liver fibrosis: current situation and future prospects. World J Gastroenterol. 2015;21(3): 742-58.

5. Schwartz RE, et al. Multipotent adult progenitor cells from bone marrow differentiate into functional hepatocyte-like cells. J Clin Invest. 2002;109(10): 1291-302.

6. Wei $X$, et al. Mesenchymal stem cells: a new trend for cell therapy. Acta Pharmacol Sin. 2013;34(6):747-54.

7. Munir H, McGettrick HM. Mesenchymal stem cell therapy for autoimmune disease: risks and rewards. Stem Cells Dev. 2015;24(18):2091-100.

8. Duijvestein $M$, et al. Autologous bone marrow-derived mesenchymal stromal cell treatment for refractory luminal Crohn's disease: results of a phase I study. Gut. 2010:59(12):1662-9.

9. Sun $L$, et al. Mesenchymal stem cell transplantation reverses multiorgan dysfunction in systemic lupus erythematosus mice and humans. Stem Cells. 2009;27(6):1421-32.

10. Li $X Y$, et al. Long-term culture in vitro impairs the immunosuppressive activity of mesenchymal stem cells on T cells. Mol Med Rep. 2012;6(5): 1183-9.

11. Prasanna SJ, et al. Pro-inflammatory cytokines, IFNgamma and TNFalpha, influence immune properties of human bone marrow and Wharton jelly mesenchymal stem cells differentially. PLoS One. 2010;5(2):e9016.

12. Watt AJ, Garrison WD, Duncan SA. HNF4: a central regulator of hepatocyte differentiation and function. Hepatology. 2003;37(6):1249-53.

13. Parviz F, et al. Hepatocyte nuclear factor 4alpha controls the development of a hepatic epithelium and liver morphogenesis. Nat Genet. 2003;34(3):292-6.

14. Ning BF, et al. Hepatocyte nuclear factor 4 alpha suppresses the development of hepatocellular carcinoma. Cancer Res. 2010;70(19):7640-51.

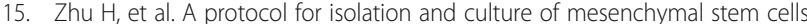
from mouse compact bone. Nat Protoc. 2010;5(3):550-60.

16. Jin $\mathrm{S}$, et al. Mesenchymal stem cells with enhanced $\mathrm{BCl}-2$ expression promote liver recovery in a rat model of hepatic cirrhosis. Cell Physiol Biochem. 2016:40(5):1117-28.

17. Shi $Y$, et al. Mesenchymal stem cells: a new strategy for immunosuppression and tissue repair. Cell Res. 2010;20(5):510-8.

18. Ren $\mathrm{G}$, et al. Mesenchymal stem cell-mediated immunosuppression occurs via concerted action of chemokines and nitric oxide. Cell Stem Cell. 2008; 2(2):141-50.

19. Shi $Y$, et al. How mesenchymal stem cells interact with tissue immune responses. Trends Immunol. 2012:33(3):136-43.

20. Shi $\mathrm{C}$, et al. Bone marrow mesenchymal stem and progenitor cells induce monocyte emigration in response to circulating toll-like receptor ligands. Immunity. 2011;34(4):590-601.

21. Bilzer M, Roggel F, Gerbes AL. Role of Kupffer cells in host defense and liver disease. Liver Int. 2006;26(10):1175-86

22. $\mathrm{Xu} \mathrm{G}$, et al. C/EBPbeta mediates synergistic upregulation of gene expression by interferon-gamma and tumor necrosis factor-alpha in bone marrow-derived mesenchymal stem cells. Stem Cells. 2009;27(4): 942-8.

23. Pittenger MF, et al. Multilineage potential of adult human mesenchymal stem cells. Science. 1999;284(5411):143-7.

24. Chan J, et al. Galectin-1 induces skeletal muscle differentiation in human fetal mesenchymal stem cells and increases muscle regeneration. Stem Cells. 2006;24(8):1879-91.

25. Ishii $\mathrm{K}$, et al. Hepatic differentiation of human bone marrow-derived mesenchymal stem cells by tetracycline-regulated hepatocyte nuclear factor 3beta. Hepatology. 2008;48(2):597-606.

26. Yang $\mathrm{S}$, et al. Conditioned medium from human amniotic epithelial cells may induce the differentiation of human umbilical cord blood mesenchymal stem cells into dopaminergic neuron-like cells. J Neurosci Res. 2013:91(7):978-86.

27. da Silva Meirelles L, Chagastelles PC, Nardi NB. Mesenchymal stem cells reside in virtually all post-natal organs and tissues. J Cell Sci. 2006;119(Pt 11: 2204-13.

28. Williams JT, et al. Cells isolated from adult human skeletal muscle capable of differentiating into multiple mesodermal phenotypes. Am Surg. 1999;65(1):22-6. 
29. Hoogduijn MJ, et al. Human heart, spleen, and perirenal fat-derived mesenchymal stem cells have immunomodulatory capacities. Stem Cells Dev. 2007;16(4):597-604.

30. English K, French A, Wood KJ. Mesenchymal stromal cells: facilitators of successful transplantation? Cell Stem Cell. 2010;7(4):431-42.

31. Lee $\mathrm{RH}$, et al. Intravenous hMSCs improve myocardial infarction in mice because cells embolized in lung are activated to secrete the antiinflammatory protein TSG-6. Cell Stem Cell. 2009;5(1):54-63.

Ready to submit your research? Choose BMC and benefit from:

- fast, convenient online submission

- thorough peer review by experienced researchers in your field

- rapid publication on acceptance

- support for research data, including large and complex data types

- gold Open Access which fosters wider collaboration and increased citations

- maximum visibility for your research: over $100 \mathrm{M}$ website views per year

At $B M C$, research is always in progress.

Learn more biomedcentral.com/submissions 